\title{
RESEARCH
}

Open Access

\section{Cardiovascular magnetic resonance assessment of acute cardiovascular effects of voluntary apnoea in elite divers}

\author{
L. Eichhorn ${ }^{1 * \dagger} \mathbb{D}$, J. Doerner ${ }^{2,3 \dagger}$, J. A. Luetkens ${ }^{2}$, J. M. Lunkenheimer ${ }^{2}$, R. C. Dolscheid-Pommerich ${ }^{4}$, F. Erdfelder ${ }^{1}$, \\ R. Fimmers ${ }^{5}$, J. Nadal ${ }^{5}$, B. Stoffel-Wagner ${ }^{4}$, H. H. Schild ${ }^{2}$, A. Hoeft ${ }^{1}$, B. Zur ${ }^{4+}$ and C. P. Naehle ${ }^{2,3+}$
}

\begin{abstract}
Background: Prolonged breath holding results in hypoxemia and hypercapnia. Compensatory mechanisms help maintain adequate oxygen supply to hypoxia sensitive organs, but burden the cardiovascular system.

The aim was to investigate human compensatory mechanisms and their effects on the cardiovascular system with regard to cardiac function and morphology, blood flow redistribution, serum biomarkers of the adrenergic system and myocardial injury markers following prolonged apnoea.
\end{abstract}

Methods: Seventeen elite apnoea divers performed maximal breath-hold during cardiovascular magnetic resonance imaging (CMR). Two breath-hold sessions were performed to assess (1) cardiac function, myocardial tissue properties and (2) blood flow. In between CMR sessions, a head MRI was performed for the assessment of signs of silent brain ischemia. Urine and blood samples were analysed prior to and up to $4 \mathrm{~h}$ after the first breath-hold.

Results: Mean breath-hold time was $297 \pm 52 \mathrm{~s}$. Left ventricular (LV) end-systolic, end-diastolic, and stroke volume increased significantly $(p<0.05)$. Peripheral oxygen saturation, LV ejection fraction, LV fractional shortening, and heart rate decreased significantly $(p<0.05)$. Blood distribution was diverted to cerebral regions with no significant changes in the descending aorta. Catecholamine levels, high-sensitivity cardiac troponin, and NT-pro-BNP levels increased significantly, but did not reach pathological levels.

Conclusion: Compensatory effects of prolonged apnoea substantially burden the cardiovascular system. CMR tissue characterisation did not reveal acute myocardial injury, indicating that the resulting cardiovascular stress does not exceed compensatory physiological limits in healthy subjects. However, these compensatory mechanisms could overly tax those limits in subjects with pre-existing cardiac disease. For divers interested in competetive apnoea diving, a comprehensive medical exam with a special focus on the cardiovascular system may be warranted.

Trial registration: This prospective single-centre study was approved by the institutional ethics committee review board. It was retrospectively registered under ClinicalTrials.gov (Trial registration: NCT02280226. Registered 29 October 2014).

Keywords: Hypoxia, Apnoea, Cardiac function, CMR, Catecholamine, hs-cT

\footnotetext{
* Correspondence: lars.eichhorn@ukbonn.de

${ }^{\dagger}$ L. Eichhorn, J. Doerner, B. Zur and C. P. Naehle contributed equally to this

work.

'Department of Anaesthesiology and Intensive Care Medicine, University

Hospital of Bonn, Bonn, Germany

Full list of author information is available at the end of the article
}

(c) The Author(s). 2018 Open Access This article is distributed under the terms of the Creative Commons Attribution 4.0 International License (http://creativecommons.org/licenses/by/4.0/), which permits unrestricted use, distribution, and reproduction in any medium, provided you give appropriate credit to the original author(s) and the source, provide a link to the Creative Commons license, and indicate if changes were made. The Creative Commons Public Domain Dedication waiver (http://creativecommons.org/publicdomain/zero/1.0/) applies to the data made available in this article, unless otherwise stated. 


\section{Background}

Hypoxia is associated with significant changes to the cardiovascular system. It is known from animal studies that hypoxia is associated with increased mean arterial blood pressure and altered myocardial morphometry due to increased left ventricular (LV) end-diastolic pressure with lengthening of end-diastolic and end-systolic myocardial fibres $[1,2]$. In humans, prolonged breath-hold - also termed [voluntary] apnoea - can be used for studying the cardiovascular adaptations to acute dynamic hypoxemia and hypercapnia [3, 4]. Trained apnoea divers are able to achieve breath-hold durations of more than 6 minutes on a regular basis. Apnoea itself leads to hypoxia and hypercapnia, both in turn leading to an activation of the sympathetic nervous system and ultimately causing peripheral vasoconstriction [5]. At the end of apnoea, trained breathhold divers can achieve hypoxic states with end tidal $\mathrm{pO}_{2}$ levels of $<30 \mathrm{mmHg} \mathrm{O}_{2}$ [6, 7]. Adequate oxygen supply of hypoxia sensitive organs (e. g. the brain) is assured by the so-called diving response, which initiates a preferential redistribution of blood flow to the brain and the heart $[3,8]$. The diving response comprises bradycardia and peripheral vasoconstriction, with the latter causing severe hypertension. In some cases cardiac complications such as cardiac arrhythmias were observed $[8,9]$, possibly due to a transient, but marked LV dilation during prolonged apnoea [10]. Whether voluntary apnoea with its cardiovascular burden leads to measurable changes of cardiac biomarkers, especially those with high sensitivity, as a precursor of cardiomyocyte injury has not been evaluated yet.

Cardiovascular magnetic resonance (CMR) is a standard non-invasive method for functional analysis of the heart [11], which allows for a high-resolution, threedimensional anatomical and functional visualization of the heart. Furthermore, CMR facilitates quantitative assessment of blood flow in the vascular system and can therefore determine fast and repetitive blood flow distribution under apnoea.

The aim of this study was to investigate cardiovascular effects during maximal apnoea in elite healthy subjects and to determine the accompanied blood flow redistribution. Cardiac biomarkers and serum markers of the adrenergic system were determined. Cerebral MRI was performed after maximal apnoea to detect potential brain injury.

\section{Methods}

\section{Inclusion and exclusion criteria}

Inclusion criteria were experience in apnoea diving with a minimum breath-hold time of $270 \mathrm{~s}$, a minimum age of 18 years, an unremarkable history of cardiac and lung disease, and the absence of long-term medication. Exclusion criteria were any contraindication to CMR or any known heart or lung disease. Participants were required not to drink caffeine-containing drinks and were instructed not to eat at least $8 \mathrm{~h}$ before the examination.

All study subjects received an information sheet 14 days prior to the study. Informed consent was obtained from all participants prior to study inclusion. Participants were questioned about training protocols and diving experience.

\section{Study protocol}

The study protocol comprised two apnoea sessions of individual maximum breath-hold combined with CMR measurements (one "functional cardiac session" and one "flow session"). Participants were asked to perform their usual pre-apnoea routines (yoga and breathing exercises). Fifteen minutes before CMR the participants were required to stop with their individual exercises and to breathe normally. A maximum of three deep inspirations prior to the final breath-hold was allowed. Hyperventilation was not allowed. Apnoea was performed as long as the individual subjects were able to withstand the breathing reflex.

This "individual" approach close to personal best breath-hold amplifies the redistribution effects and supposedly exhibits the maximum effect on the cardiovascular system. Additionally, a brain MRI was performed at least 30 minutes after the first of the two breath-hold sessions to detect acute brain ischemia. Cardiac biomarkers and catecholamines were evaluated to detect cardiac damage (for time points see Fig. 1).

\section{Magnetic resonance imaging technique}

All CMR studies were performed during voluntary breath-hold in maximal inspiration and in supine position using a 1.5 Tesla whole body scanner (Ingenia, Philips Healthcare, Best, The Netherlands). The protocol for the "functional cardiac session" consisted of retrospectively gated balanced steady state free precision cine imaging with 30 cardiac phases per slice. To assess functional changes under apnoea, three short axis (apical, midventricular, basal) cines as well as a vertical long axis cine were acquired repeatedly over the course of apnoea. T2-mapping - indicative of myocardial oedema using a gradient-spin-echo technique was performed in the same three slices in short axis orientation as the steady state free precision cine images prior and immediately after maximal apnoea [12].

MRI of the brain was performed using a 3 Tesla MRI scanner (Ingenia, Philips Healthcare) using a dedicated head coil. The protocol comprised a transverse T2-weighted turbo spin echo (TSE), a transverse fluid attenuated inversion recovery (FLAIR), a transverse $\mathrm{T} 2 \%$, a sagittal $\mathrm{T} 1$-weighted $3 \mathrm{D}$ gradient echo, 


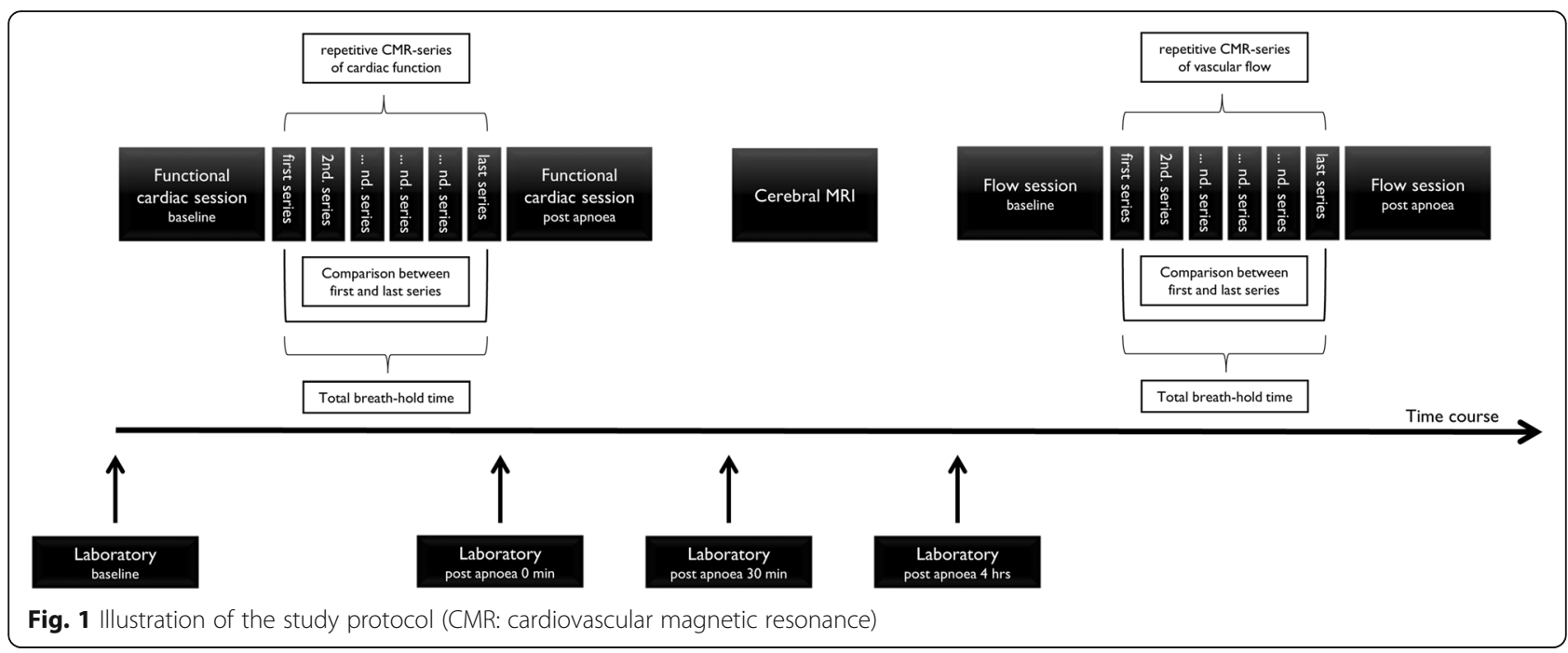

and a transverse as well as a coronal diffusion weighted imaging (DWI) sequence.

The second CMR session was performed at least $4 \mathrm{~h}$ after the first "functional" cardiac session. This session was focused on flow measurements in the ascending and descending aorta, the pulmonary trunk, and both common carotid arteries using common 2D phase contrast imaging.

\section{Image analysis}

Two radiologists blinded to the study protocol independently evaluated all images. The first (apnoea $a_{\text {early }}$ ) and last completed imaging data set (apnoea $a_{\text {late }}$ ) of each maximum apnoea were compared. Global cardiac function at resting conditions (left ventricular end-diastolic volume (LVEDV), end-systolic volume (LVESV), stroke volume (LVSV), and ejection fraction (LVEF) were determined from the short axis (ViewForum, Philips Healthcare) and normalized to the body surface area (BSA) using Mosteller's formula [13]. LVEDV and LVESV were quantified manually by tracing the endocardial borders in all short axis slices. For functional parameters under apnoea LV volumes were determined using the modified Simpson rule. For the assessment of regional cardiac function, fractional shortening (FS) was assessed as described previously [14]. In short, the endocardial distance from the free LV lateral wall to the septal wall was measured in end-diastole (EDD) and end-systole (ESD) in apical, midventricular and basal slices in short axis orientation. FS was then calculated as followed: $F S=\frac{E D D-E S D}{E D D} \times 100$. For flow quantification, phase contrast imaging was analysed using dedicated software (ViewForum, Philips Healthcare). Borders of the ascending and the descending aorta, the pulmonary trunk and both common carotid arteries (CCA) were manually traced in the magnitude images and the region of interest was automatically copied to phase images with manual correction performed when deemed necessary. Maximum velocity $\left(\mathrm{V}_{\text {max }}\right)$, mean velocity $\left(\mathrm{V}_{\text {mean }}\right)$, mean flow $\left(\mathrm{Q}_{\text {mean }}\right)$ and absolute stroke volume (SV) was assessed, respectively. T2 relaxation times were extracted from the T2 maps that were generated by using dedicated software (Intellispace Portal 9.0, Philips Healthcare). A circular region of interest (ROI) was then manually placed in the septal and lateral LV wall and averaged.

Cerebral MRI was analysed by the same two radiologists for focal diffusion restrictions as a sign of acute cerebral ischemia, cerebral micro-bleedings, and incidental findings. Peripheral oxygen saturation $\left(\mathrm{SpO}_{2}\right)$ and heart rate (HR) were measured continuously during both CMR sessions using a CMR-compatible device (Expression MR400, Invivo, Gainesville, Florida, USA).

\section{Estimation of myocardial oxygen demand}

Myocardial oxygen demand was estimated using the modified pressure work index as previously described $\left(\mathrm{PWI} \bmod =\right.$ modified pressure work load index, $\mathrm{P}_{\text {systolic }}=$ systolic blood pressure, $\mathrm{P}_{\text {diastolic }}=$ diastolic blood pressure, $\mathrm{HR}=$ heart rate, $\mathrm{CO}=$ cardiac output, $\mathrm{BSA}=$ body surface area) [15]:

$$
\begin{aligned}
\text { PWImod }= & 0.02+\left(P_{\text {systolic }} \times H R \times 8.37 \times 10^{-4}\right) \\
& +\left(0.8 \times P_{\text {systolic }}+0.2 \times P_{\text {diasystolic }}\right) \\
& \left.\times \frac{C O}{B S A} \times 8 \times 10^{-5}\right)
\end{aligned}
$$

\section{Laboratory testing}

Urine was collected for baseline measurements $30 \mathrm{~min}$ before the first apnoea session started and $4 \mathrm{~h}$ thereafter, but before starting the second CMR session. Catecholamine levels, N-terminal pro-hormone of brain natriuretic peptide (NT pro-BNP), brain natriuretic peptide (BNP) 
and high sensitive troponin (hs-cT) were analysed from venous blood samples taken before, immediately after, $30 \mathrm{~min}$, and $4 \mathrm{~h}$ after the first apnoea. All results (urine and blood samples) therefore reflect the effect of the first single breath-hold, but not those of repetitive apnoeal stages.

\section{Laboratory analyses}

NT-pro BNP measurements were performed immediately after blood collection under routine conditions with the LOCI $^{\mathrm{mi}}$-based NT-proBNP assay for Dimension ${ }^{\mathrm{Tm}}$ VISTA 1500 (Siemens Healthcare Diagnostics, Eschborn, Germany). For BNP, hs-cT, and catecholamine analysis, aliquots were stored at $-80^{\circ} \mathrm{C}$. BNP and hs-cT were measured using commercially available, specific immunoassays (BNP and STA High Sensitive Troponin-I assay for ARCHITECT $^{\mathrm{Tm}}$, both Abbott Diagnostics, Wiesbaden, Germany). Plasma catecholamine levels were analyzed using a catecholamine reagent kit (Chromsystems Instruments \& Chemicals GmbH; ord. no. 5000; Graefelfing, Germany) with a HPL Chromatography (Waters Corporation, Milford, Massachusetts, USA). Urine catecholamines were analysed by Bio Rad HPLC Agilent 1100 Series (Agilent Technologies, Waldbronn, Germany).

\section{Statistical analysis}

Data are presented as mean +/- standard deviation (SD). Statistical analysis was performed using GraphPad Prism (version 7.02 for Windows, GraphPad Software, La Jolla, California, USA) and SAS version 9.4 (SAS Institut Inc., Cary, North Carolina, USA). Descriptive statistics are summarised as means and standard deviation $( \pm S D)$. All parameters were compared using paired t-testing. Correlations were calculated using the Spearman's rank correlation analysis. Statistical significance was defined as $p<0.05$.

\section{Results}

Seventeen elite apnoea divers (15 men) age of $40 \pm 11$ years were investigated under maximum breath-hold (height $183 \pm 8 \mathrm{~cm}$, weight $82 \pm 11 \mathrm{~kg}$, BSA $2.0 \pm 0.17 \mathrm{~kg} / \mathrm{m}^{2}$ and body mass index (BMI) $24.4 \pm 2.3 \mathrm{~kg} / \mathrm{m}^{2}$ ). Five of 17 divers regularly participate in various national and international competitions. The training frequency was $2.2 \pm 1.6$ training sessions a week. Training content and focus varied inter-individually. The breath-hold experience of all athletes was $4.5 \pm 2.6$ years. The personal breath-hold records were 5:20 \pm 0:49 min. No comorbidities were found in any diver. Five divers have had a hypoxic blackout in their history.

Maximal breath-hold time in the "functional cardiac session" was $413 \mathrm{~s}$ and maximal breath-hold time in the "flow session" was $483 \mathrm{~s}$. Mean time of breath-hold in the "functional cardiac session" was $297 \pm 52 \mathrm{~s}$ and $276 \pm 80 \mathrm{~s}$ in the "flow session" $(p=0.14) . \mathrm{SpO}_{2}$ levels gradually decreased from $99 \pm 1 \%$ to $74 \pm 14 \%(p<0.001)$ in the "functional cardiac session" and from $99 \pm 1 \%$ to $77 \pm 15 \%$ $(p<0.001)$ in the "flow session". No hypoxic loss of consciousness was observed. Physiological data of each participant are listed in Table 1.

\section{Cardiac functional analysis}

In all participants, LVEDV, LVESV, and LVSV increased from onset to the end of apnoea $(122.9 \pm 24.2 \mathrm{ml}$ vs. $176.9 \pm$ $26.4 \mathrm{ml}, p<0.001 ; 47.3 \pm 16.8 \mathrm{ml}$ vs. $75.9 \pm 16.3 \mathrm{ml}, p<$ $0.001 ; 75.6 \pm 16.9 \mathrm{ml}$ vs. $101.0 \pm 22.9 \mathrm{ml}, p=0.003$ ) (Fig. 2a), while LVEF (Fig. 2b) decreased from $61.8 \pm$ $9.4 \%$ to $56.8 \pm 8.2 \%(p=0.04)$. Despite a significant decrease of HR ( $75 \pm 23 \mathrm{bpm}$ vs. $61 \pm 12 \mathrm{bpm}$; $p=0.028$ ) (Fig. 2c), LV-CO remained unchanged $(5.5 \pm 1.6 \mathrm{l} / \mathrm{min}$ vs. $6.1 \pm 1.7 \mathrm{l} / \mathrm{min}, p=0.88$ ) (Fig. $2 \mathrm{~d}$ ). A representative image series of gradual LV enlargement is shown in Fig. 3. FS decreased over the course of apnoea from $33.0 \pm 6.0 \%$ to $23.8 \pm 4.4 \%(p<0.001)$, with the decrease in the apical slice $(41.5 \pm 7.4 \%$ vs. $27.9 \pm 7.2 \%$, $p<0.001)$ and the midventricular slice $(30.7 \pm 9.0 \%$ vs. $21.6 \pm 4.4 \%, p<0.001)$, whereas only a non-significant trend was observed in the basal slice $(26.7 \pm 7.1 \%$ vs. $22.6 \pm 5.5 \%, p=0.065$ ) (see also Table 2).

Changes in HR $(\Delta \mathrm{HR})$ over the course of apnoea (Fig. 4) showed a significant negative correlation with the changes of LVSV ( $\triangle$ LVSV) (Spearman's rank correlation analysis; correlation coefficient $-0.64, p=0.008$ ). Additionally, $\Delta$ HR over the course of apnoea had a significant negative correlation with the change of LVEDV ( $\triangle$ LVEDV) (Spearman's rank correlation analysis; $-0.59 ; p=0.016$ ). This was less prominent when $\triangle$ LVEDV was normalized to BSA (Spearman's rank correlation analysis; $0.55 ; p=0.028)$. In contrast, there was only a weak correlation between $\triangle \mathrm{HR}$ and an increase in $\triangle \mathrm{LVESV}$ $(-0,319 ; p=0.23)$.

\section{Quantitative flow analysis}

While SV, $\mathrm{V}_{\text {max }}, \mathrm{V}_{\text {mean }}$, and $\mathrm{Q}_{\text {mean }}$ increased significantly in the ascending aorta and the pulmonary trunk during apnoea, no changes were observed in the descending aorta, indicating a preferential blood flow distribution to the heart and the brain. In addition, both CCAs showed a significant increase in SV (see Fig. 5), $\mathrm{V}_{\text {mean }}$ and $\mathrm{Q}_{\text {mean }}$ over the course of apnoea. All flow measurements are summarised in Table 3. A relevant shunt was neither observed at rest nor under apnoea (Qp/Qs: $1.06 \pm 0.25$ vs. $1.06 \pm 0.19 ; p=0.97$ ).

\section{Calculation of myocardial oxygen demand and oxygen supply}

We found a decrease in HR $(76 \pm 23$ bpm vs. $61 \pm$ $12 \mathrm{bpm})$ and an increase in LVSV $(75.6 \pm 16.9 \mathrm{ml}$ vs. 
Table 1 Demographical and physical characteristics of all apnoea divers

\begin{tabular}{|c|c|c|c|c|c|c|c|c|c|c|}
\hline Participants & $\begin{array}{l}\text { Age } \\
\text { [years] }\end{array}$ & Sex & $\begin{array}{l}\text { Height } \\
{[\mathrm{cm}]}\end{array}$ & $\begin{array}{l}\text { Weight } \\
{[\mathrm{kg}]}\end{array}$ & $\begin{array}{l}\text { Time of } \\
\text { 1st BH [s] } \\
\text { cardiac } \\
\text { session }\end{array}$ & $\begin{array}{l}\text { Baseline } \\
\mathrm{SpO}_{2}[\%] \\
\text { cardiac } \\
\text { session }\end{array}$ & $\begin{array}{l}\text { Minimal } \\
\mathrm{SpO}_{2}[\%] \\
\text { cardiac } \\
\text { session }\end{array}$ & $\begin{array}{l}\text { Time of } \\
\text { 2nd BH [s] } \\
\text { flow session }\end{array}$ & $\begin{array}{l}\text { Baseline } \\
\mathrm{SpO}_{2}[\%] \\
\text { flow session }\end{array}$ & $\begin{array}{l}\text { Minimal } \\
\mathrm{SpO}_{2}[\%] \\
\text { flow session }\end{array}$ \\
\hline 1 & 58 & male & 175 & 80 & 200 & 99 & 89 & 194 & 99 & 87 \\
\hline 2 & 23 & male & 185 & 73 & 255 & 100 & 92 & 274 & 99 & 86 \\
\hline 3 & 36 & male & 183 & 79 & 233 & 99 & 76 & 272 & 99 & 39 \\
\hline 4 & 51 & male & 193 & 86 & 318 & 99 & 68 & 298 & 98 & 52 \\
\hline 5 & 35 & male & 186 & 70 & 293 & 99 & 73 & 262 & 98 & 79 \\
\hline 6 & 53 & female & 166 & 76 & 268 & 99 & 52 & 162 & 99 & 89 \\
\hline 7 & 46 & male & 180 & 73 & 348 & 98 & 82 & 302 & 99 & 87 \\
\hline 8 & 38 & female & 176 & 67 & 310 & 98 & 66 & 299 & 99 & 72 \\
\hline 9 & 30 & male & 178 & 75 & 413 & 99 & 55 & 377 & 99 & 56 \\
\hline 10 & 24 & male & 200 & 110 & 278 & 99 & 89 & 267 & 99 & 89 \\
\hline 11 & 35 & male & 176 & 70 & 328 & 99 & 89 & 237 & 98 & 91 \\
\hline 12 & 29 & male & 186 & 86 & 366 & 99 & 71 & 483 & 97 & 76 \\
\hline 13 & 46 & male & 183 & 91 & 295 & 99 & 81 & 264 & 99 & 87 \\
\hline 14 & 31 & male & 185 & 85 & 263 & 98 & 79 & 249 & 100 & 86 \\
\hline 15 & 50 & male & 189 & 86 & 278 & 97 & 75 & 254 & 99 & 82 \\
\hline 16 & 56 & male & 190 & 89 & 362 & 99 & 44 & 377 & 99 & 58 \\
\hline 17 & 36 & male & 185 & 98 & 249 & 100 & 85 & 132 & 99 & 91 \\
\hline$\varnothing$ & 40 & & 183 & 82 & 297 & 99 & 74 & 277 & 99 & 77 \\
\hline SD & 11 & & 8 & 11 & 53 & 1 & 14 & 80 & 1 & 15 \\
\hline
\end{tabular}

$\mathrm{BH}$ breath-hold, $\mathrm{SpO}_{2}$ peripheral oxygen saturation

$95.1 \pm 32.6 \mathrm{ml})$ in this study. Using a previously reported increase of systolic and diastolic blood pressure from 135 $\pm 13 \mathrm{mmHg}$ to $185 \pm 25 \mathrm{mmHg}$ [16], the estimated myocardial oxygen demand using the modified pressure work index [15] increases from $8.51 \mathrm{ml} / \mathrm{min} / 100 \mathrm{~g}$ to $9.48 \mathrm{ml} /$ $\mathrm{min} / 100 \mathrm{~g}$ (increase of $11 \%$ ) during apnoea.

\section{T2 mapping}

Compared to baseline values, T2 relaxation times showed no significant change $(51.7 \pm 2.4 \mathrm{~ms}$ vs. $52.6 \pm$ $2.5 \mathrm{~ms}, p>0.05)$.

\section{Laboratory analysis of catecholamine levels, NT pro-BNP, hs-cT, BNP}

Serum catecholamine levels (see Fig. 6a, b) showed a fast, increase immediately after apnoea onset (epinephrine from $67.5 \pm 23.9 \mathrm{pg} / \mathrm{ml}$ to $173.8 \pm 113.2 \mathrm{pg} / \mathrm{ml}(p<0.001)$; norepinephrine from $590 \pm 197 \mathrm{pg} / \mathrm{ml}$ to $2063 \pm 1703 \mathrm{pg} / \mathrm{ml}$ ( $p$ $<0.001)$ ). Serum catecholamine levels returned to baseline values as early as $30 \mathrm{~min}$ post apnoea (epinephrine: $50.9 \pm$ $26.6 \mathrm{pg} / \mathrm{ml}$; norepinephrine: $474.5 \pm 138.1 \mathrm{pg} / \mathrm{ml})$. Catecholamine levels derived from urine samples still showed a slight, but significant increase $4 \mathrm{~h}$ after apnoea compared to baseline conditions (epinephrine from $6.1 \pm 2.0 \mathrm{pg} / \mathrm{ml}$ to
$11.3 \pm 6.1 \mathrm{pg} / \mathrm{ml}, p=0.003$; norepinephrine from $25.0 \pm$ $20.1 \mathrm{pg} / \mathrm{ml}$ to $42.3 \pm 22.6 \mathrm{pg} / \mathrm{ml}, p=0.011)$.

NT pro-BNP increased slightly from baseline levels $45.9 \pm 40.3 \mathrm{pg} / \mathrm{ml}$ to $49.3 \pm 43.3 \mathrm{pg} / \mathrm{ml}$ immediately after apnoea $(p=0.011)$ and to $53.8 \pm 49.4 \mathrm{pg} / \mathrm{ml}(p=$ 0.037) $4 \mathrm{~h}$ after breath-hold (see Fig. 6c). BNP could not be quantified in 7 out of 17 subjects due to values lower than the detection limit $(<10 \mathrm{pg} / \mathrm{ml})$. Overall, there were no significant changes of BNP serum levels at any time point.

Hs-cT increased from baseline until $4 \mathrm{~h}$ after apnoea $(2.2 \pm 1.1 \mathrm{pg} / \mathrm{ml}$ vs. $3.1 \pm 1.7 \mathrm{pg} / \mathrm{ml}, p=0.026)$ (Fig. 6d). Compared to baseline levels, this resulted in a mean relative $\mathrm{Hs}-\mathrm{cT}$ increase of $56 \%$, but was still far from any pathological range.

\section{Cerebral MRI}

DWI revealed neither acute nor sub-acute signs of cerebral ischemia. In one participant, a clinically irrelevant singular micro-bleeding formation located in the brain stem was observed. In two participants, unilateral fluid collections of the mastoid were observed and reported. No further incidental findings were observed. 

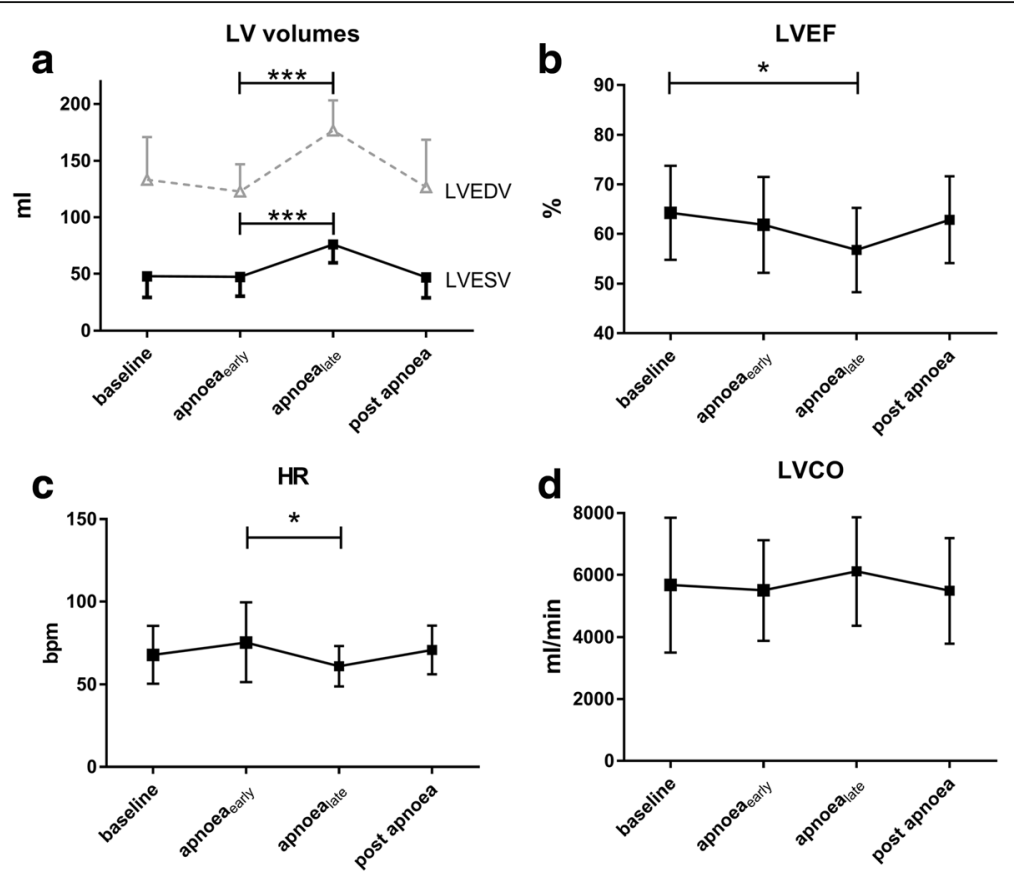

Fig. 2 Left ventricular changes during apnoea. a) LV volumes: left ventricular volumes. b) LVEF: left ventricular ejection fraction, c) HR: heart rate, d) LVCO: left ventricular cardiac output ( ${ }^{*} p=<0.05 ;{ }^{* *} p=<0.01 ;{ }^{* *} p=<0.001 ;{ }^{* * *} p=<0.0001$ ). Values are expressed as mean \pm standard deviation

\section{Discussion}

In this present study, a holistic approach with stateof-the-art cardiac function evaluation, tissue characterization and biomarker analysis was performed to evaluate myocardial function, thoracic and supra-aortic blood flow, and their changes during maximal individual apnoea. The major findings of our study are a stepwise (1) increase of LVEDV, LVESV, LVSV and an unchanged CO, (2) decrease of LVEF and FS at the end of apnoea, (3) increase of supra-aortic blood flow without concurring flow changes in the descending aorta, and (4) an elevated hs-cT and NT-pro-BNP levels.

\section{Cardiac function}

In the present study we were able to demonstrate a significant LV dilatation along with an increased LVSV, which is in line with a previous study [17], where increased EDD and ESD, an increase in SV and CO and a reduction in contractile function after an apnoea time of $3.7 \pm 0.3$ min was reported. In contrast to our results, neither bradycardia nor increased calculated systemic vascular resistance were observed [17], although both effects are part of the accepted concept of the diving response [8]. In a more recent study by Batinic et al., cardiac parameters (i.e. HR, LV volumes, LVEF, LVCO) taken at two time points of apnoea (minute 1 and

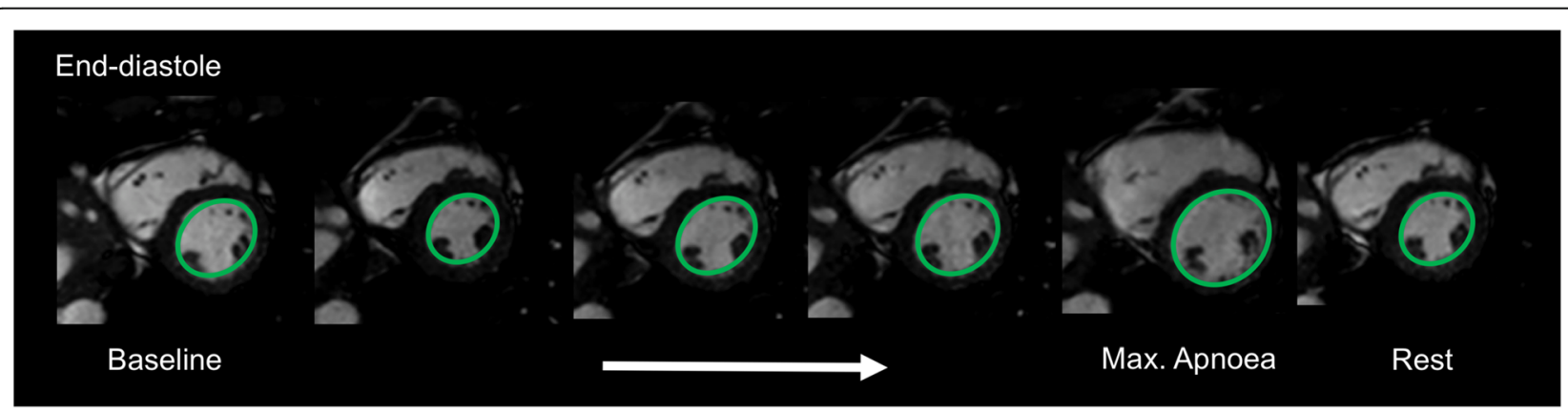

Fig. 3 Representative image showing a progressive LV dilation over the course of apnoea in diastolic heart phase (subject 12) 
Table 2 Parameters of CMR functional cardiac session

\begin{tabular}{|c|c|c|c|c|c|c|c|}
\hline $\begin{array}{l}\text { CMR functional } \\
\text { cardiac session }\end{array}$ & $\begin{array}{l}\text { Baseline } \pm S D \\
\text { before apnoea }\end{array}$ & $\begin{array}{l}\text { Begin of apnoea } \\
\pm S D \text { apnoea }\end{array}$ & $\begin{array}{l}\text { End of apnoea } \\
\pm \text { SD apnoealate }\end{array}$ & $\begin{array}{l}\text { Mean of difference } \\
\text { at beginning vs. } \\
\text { end of apnoea }\end{array}$ & $\begin{array}{l}\text { SD of } \\
\text { differences }\end{array}$ & $\begin{array}{l}95 \% \text { confidence } \\
\text { interval }\end{array}$ & $p$-value \\
\hline $\mathrm{HR}$ [bpm] & $67.9 \pm 17.0$ & $75.5 \pm 23.3$ & $61.1 \pm 11.8$ & -14.8 & 24.4 & -27.8 to -1.8 & 0.0282 \\
\hline LVEDV [ml] & $133.4 \pm 37.9$ & $122.9 \pm 24.2$ & $176.9 \pm 26.4$ & 53.4 & 28.2 & 38.3 to 68.4 & $<0.001$ \\
\hline LVESV [ml] & $48.0 \pm 18.6$ & $47.3 \pm 16.8$ & $75.9 \pm 16.3$ & 27.4 & 14.5 & 19.7 to 35.1 & $<0.001$ \\
\hline LVEF [\%] & $64.3 \pm 9.2$ & $61.8 \pm 9.4$ & $56.8 \pm 8.2$ & -4.2 & 7.5 & -8.2 to -0.2 & 0.0397 \\
\hline LVSV [ml] & $86.4 \pm 26.3$ & $75.6 \pm 16.9$ & $95.1 \pm 32.6$ & 19.5 & 34.1 & 2.0 to 37.1 & 0.0014 \\
\hline LVCO [l/min] & $5.7 \pm 2.1$ & $5.5 \pm 1.6$ & $6.1 \pm 1.7$ & 0.6 & 1.0 & 0.1 to 1.2 & 0.021 \\
\hline \multicolumn{8}{|l|}{ FS [\%] } \\
\hline apical & $43.8 \pm 5.9$ & $41.5 \pm 7.4$ & $27.9 \pm 7.2$ & -13.7 & 5.8 & -16.7 to -10.7 & $<0.0001$ \\
\hline midventricular & $33.9 \pm 7.1$ & $30.7 \pm 9.0$ & $21.6 \pm 4.4$ & -8.3 & 7.6 & -12.4 to -4.3 & 0.0005 \\
\hline basal & $30.1 \pm 5.4$ & $26.7 \pm 7.1$ & $22.6 \pm 5.5$ & -3.2 & 6.0 & -6.7 to 0.2 & 0.0646 \\
\hline mean & $35.9 \pm 4.8$ & $33.0 \pm 6.0$ & $23.8 \pm 4.4$ & -8.6 & 4.4 & -10.9 to -6.2 & $<.0001$ \\
\hline
\end{tabular}

HR heart rate, $L V E D V$ left ventricular end-diastolic volume, LVESV left ventricular end-systolic volume, LVEF left ventricular ejection fraction, $L V S V$ left ventricular stroke volume, LVCO left ventricular cardiac output, FS fractional shortening, SD standard deviation; $p$-values for begin apnoea vs. end of apnoea

minute 3) were compared [18]. These investigators found a significant increase in LVEDV and CO (112 \pm $15 \mathrm{ml}$ to $125 \pm 15 \mathrm{ml} ; 5.4 \pm 1.9 \mathrm{l} / \mathrm{min}$ to $6.0 \pm 1.2 \mathrm{l} / \mathrm{min}$ ), which was similar to our results $(123 \pm 24 \mathrm{ml}$ to $177 \pm$ $26 \mathrm{ml} ; 5.5 \pm 1.6 \mathrm{l} / \mathrm{min}$ to $6.1 \pm 1.7 \mathrm{l} / \mathrm{min})$. In contrast to the previous results from Pingitore et al. [17] and the results of the present study, no changes in SV were observed $(69 \pm 12 \mathrm{ml}$ to $69 \pm 8 \mathrm{ml})$, while HR increased from $80 \pm 15 \mathrm{bmp}$ to $87 \pm 16 \mathrm{bmp}$ during apnoea [18]

Since the mammalian diving response to maximal voluntary apnoea considerably varies depending on the examined individual and the study setup, the at first apparently contradictory results of the three studies might be explained by the breath-hold duration $[5,9,19]$. In contrast to previous studies focusing on physiological changes during apnoea, the breath-hold time in the present study was considerably longer (297 \pm 99 s vs. $234 \pm 66$ s; $199 \pm 11$ s; $210 \pm 70$ s) $[5,9,19]$. However, even though individual responses may vary, it is known that physiological changes are most notable at the end of apnoea $[9,20,21]$. In this context it is important to mention that the previous studies $[17,18]$ used predefined time points for data collection, which will not necessarily coincide with the individual maximum breathhold duration of each athlete. We have therefore decided to use a minimal breath-hold duration of $270 \mathrm{~s}$ to eliminate the possible shortcomings of a too short apnoea duration in the previous studies [5, 9, 19-21]. Therefore, one can speculate that the shorter breath-hold durations registered in both previous studies [10, 17] are not suitable to push all compensatory mechanisms to their limits, and that a predefined time point might lead to undersampling. This is further supported by the fact that $\mathrm{SpO}_{2}$ decreased more profoundly in our study compared to the study from Pingitore et al. (from $99 \pm 1 \%$ to $74 \pm$ $14 \%$ vs. $97 \pm 0.2 \%$ to $84 \pm 2 \%$ ) [17].

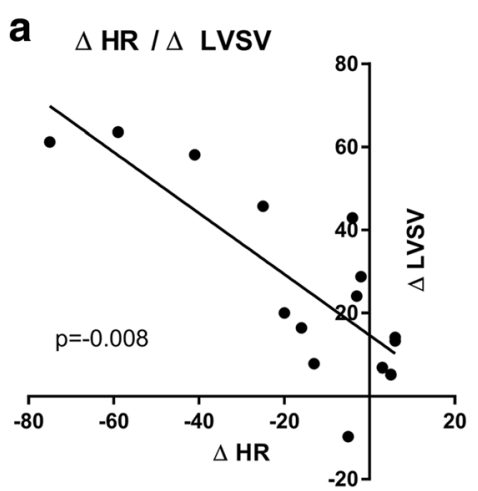

b $\triangle$ HR I $\triangle$ LVEDV

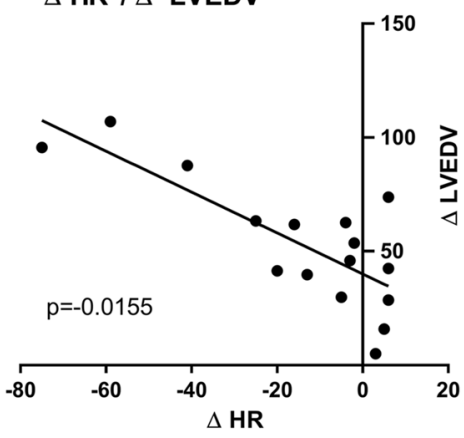

Fig. 4 Correlation of a) $\Delta H R$ (Apnoea $a_{\text {early }}$ - Apnoealate) with $\Delta$ LVSV (Apnoea early - Apnoealate, panel and b) $\Delta$ LVEDV (Apnoea early - Apnoealate, panel respectively, using Spearman's rank correlation ( $\Delta$ HR with $\Delta$ LVSV: $-0.637, p=0.008 ; \Delta$ HR with $\Delta$ LVEDV: $-0.592923 ; p=0.0155$ ). HR: heart rate, LVSV: left ventricular stroke volume; LVEDV: left ventricular end-diastolic volume 


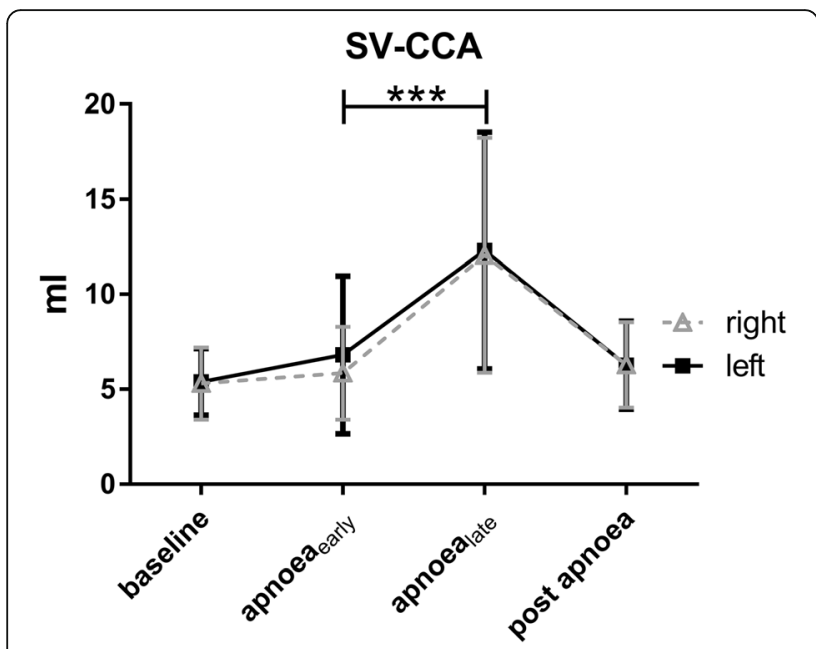

Fig. 5 Stroke volumes of common carotid arteries during course ao apnoea. SV-CCA: stroke volume in common carotid arteries. Values are expressed as mean \pm SD

We found a relative increase in LVSV of $30 \pm 48 \%$ during apnoea, but a decrease in FS and LVEF. FS depends on inter-ventricular dimensions and is affected by ventricular filling. Ejection fraction, in contrast, is a relatively load independent surrogate parameter for cardiovascular performance. In general, the efficiency of myocardial performance is determined by preload, afterload and contractility $[22,23]$. An increase in afterload will therefore result in decreased efficiency of myocardial performance. In case of prolonged breath-hold the peripheral chemoreflex regulation, the elevated sympathetic nerve activity and the increase in norepinephrine will lead to peripheral vasoconstriction and hypertension $[5,24]$ and subsequently to bradycardia via the baroreflex [25]. In accordance with this established physiological pathway, we observed a significant increase in norepinephrine levels to above the upper cut-off limit of
$>420 \mathrm{pg} / \mathrm{ml}$ and a decrease in HR at the end of apnoea. Therefore, the HR decrease and the concommitant increase of both ventricles may be seen as an indirect visualization of the aforementioned baroreflex (Fig. 4).

\section{Biomarkers}

NT-proBNP was elevated early after maximal apnoea. Although some authors describe BNP as an "emergency" cardiac hormone against ventricular overload [26], the observed elevations of pro-BNP were only minor and far from pathological levels. Nevertheless, in absence of other triggers even this small increase may be regarded as an indicator for LV wall stress. Although an increase in hs-cT was found in this study, the normal T2 relaxation times directly after apnoea may indicate that the increased hs-cT may be more attributable to the LV dilatation and not to acute and persistent myocardial damage. This may further be supported by the fact that elevated cardiac troponin (cT) levels are also commonly found in patients with dilated cardiomyopathy [27].

In addition, myocardial perfusion and oxygen consumption is dependant on various parameters. At the end of apnoea, HR decreases while SV and systolic and diastolic blood pressure increase. These physiological changes translate into an increase of estimated oxygen demand in our study from $8.5 \mathrm{ml} / \mathrm{min} / 100 \mathrm{~g}$ to $9.5 \mathrm{ml} /$ $\mathrm{min} / 100 \mathrm{~g}$ (i.e. only by $11 \%$ ). However, this increase in demand may be assumed to be outweighed by a theoretical increase of approximately $40 \%$ of coronary perfusion due to increase of the diastolic blood pressure. It is of note that these theoretical considerations are based on healthy subjects without any coronary morbidities.

\section{Clinical context}

The human diving response (i.e. bradycardia, peripheral vasoconstriction, increased blood pressure) helps to preserve $\mathrm{O}_{2}$ in case of apnoea [28]. These protective

Table 3 Parameters of CMR flow session

\begin{tabular}{|c|c|c|c|c|c|c|c|c|}
\hline Vessel & Parameter & Baseline & $\begin{array}{l}\text { Beginning of } \\
\text { apnoea }\end{array}$ & $\begin{array}{l}\text { End of } \\
\text { apnoea }\end{array}$ & $\begin{array}{l}\text { Mean } \\
\text { Difference }\end{array}$ & $\begin{array}{l}\text { SD of mean } \\
\text { differences }\end{array}$ & $\begin{array}{l}95 \% \text { confidence } \\
\text { interval }\end{array}$ & $p$-value \\
\hline \multirow[t]{2}{*}{ Ascending aorta } & stroke volume [ml] & $72.3 \pm 17.4$ & $63.9 \pm 21.3$ & $96.3 \pm 26.8$ & 32.2 & 27.7 & 17.5 to 47.0 & 0.0003 \\
\hline & $\mathrm{Q}_{\text {mean }}[\mathrm{ml} / \mathrm{s}]$ & $82.9 \pm 27.8$ & $74.3 \pm 25.9$ & $101.3 \pm 31.3$ & 29.5 & 32.2 & 12.3 to 46.7 & 0.0023 \\
\hline \multirow[t]{2}{*}{ Descending aorta } & stroke volume [ml] & $40.8 \pm 15.6$ & $35.7 \pm 16.0$ & $41.4 \pm 15.2$ & 6.0 & 20.4 & -5.3 to 17.2 & 0.2757 \\
\hline & $\mathrm{Q}_{\text {mean }}[\mathrm{ml} / \mathrm{s}]$ & $45.0 \pm 16.3$ & $38.2 \pm 10.6$ & $43.4 \pm 15.6$ & 1.9 & 18.7 & -9.4 to 13.2 & 0.7173 \\
\hline \multirow[t]{2}{*}{ Pulmonary trunk } & stroke volume $[\mathrm{ml}]$ & $71.6 \pm 31.1$ & $64.6 \pm 31.1$ & $87.3 \pm 31.8$ & 38.1 & 40.5 & 10. 9 to 65.3 & 0.0109 \\
\hline & $\mathrm{Q}_{\text {mean }}[\mathrm{ml} / \mathrm{s}]$ & $76.9 \pm 26.5$ & $63.5 \pm 15.6$ & $95.6 \pm 28.4$ & 45.3 & 32.6 & 21.9 to 68.6 & 0.0018 \\
\hline \multirow[t]{2}{*}{ Right CCA } & stroke volume [ml] & $5.3 \pm 1.8$ & $8.9 \pm 2.4$ & $12.1 \pm 5.9$ & 6.9 & 5.5 & 3.3 to 10.4 & 0.0013 \\
\hline & $\mathrm{Q}_{\text {mean }}[\mathrm{ml} / \mathrm{s}]$ & $6.1 \pm 1.4$ & $7.8 \pm 2.8$ & $11.2 \pm 3.5$ & 3.4 & 3.1 & -5.0 to -1.8 & 0.0005 \\
\hline \multirow[t]{2}{*}{ Left CCA } & stroke volume $[\mathrm{ml}]$ & $5.4 \pm 1.7$ & $6.8 \pm 4.0$ & $12.3 \pm 6.0$ & 6.9 & 5.6 & -8.0 to -2.1 & 0.0022 \\
\hline & $\mathrm{Q}_{\text {mean }}[\mathrm{ml} / \mathrm{s}]$ & $6.2 \pm 1.3$ & $7.7 \pm 2.3$ & $11.7 \pm 4.0$ & 4.0 & 3.8 & 6.0 to 2.0 & 0.0007 \\
\hline
\end{tabular}

CCA common carotid artery; $p$-values for begin apnoea vs. end of apnoea, $S D$ standard deviation, $Q_{\text {mean }}$ mean flow 

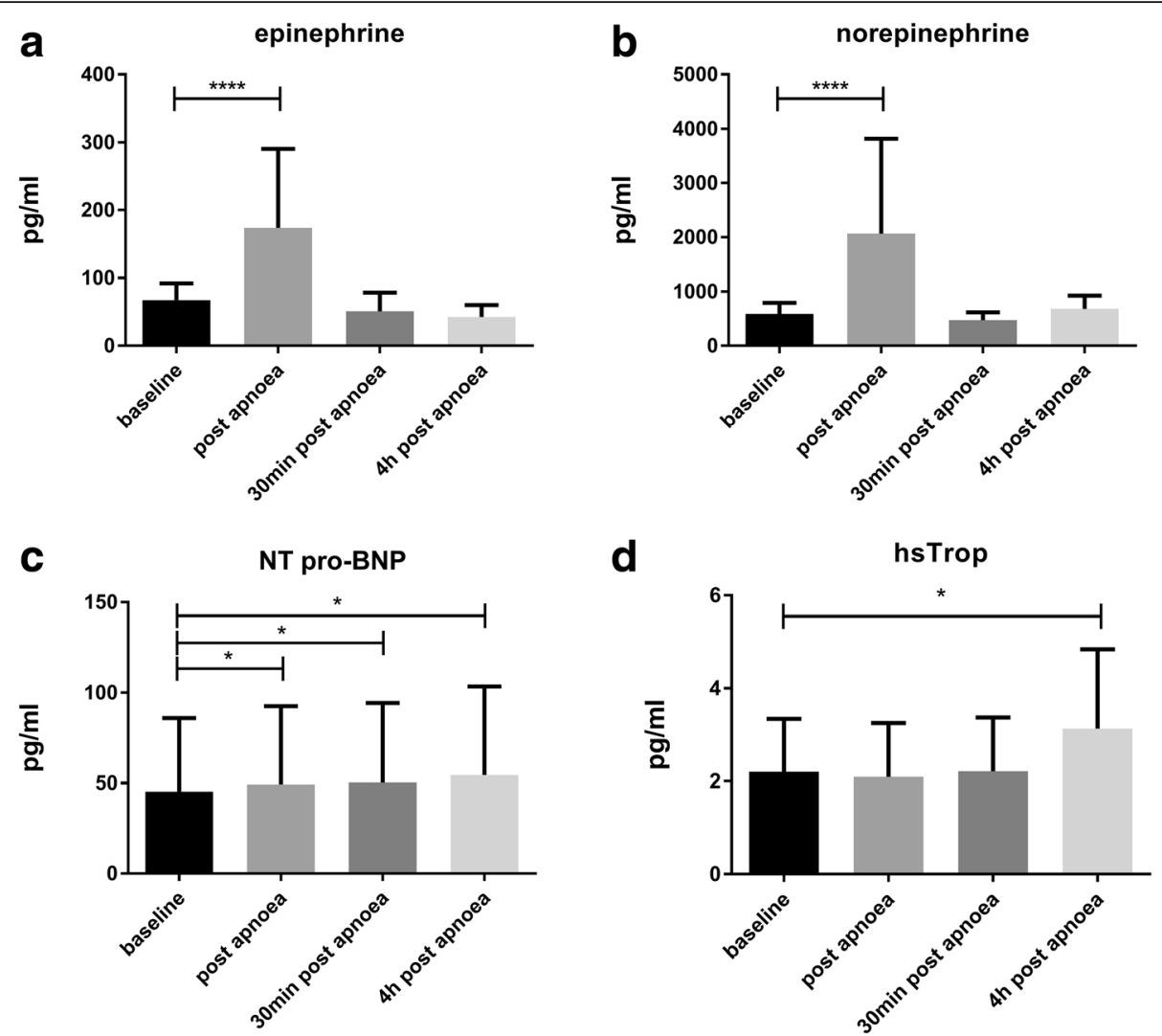

Fig. 6 Serum parameters of a) epinephrine, b) norepinephrine, c) NT pro-BNP and d) high sensitive Troponin (hsTrop) under apnoea

mechanisms against hypoxia are triggered by apnoea per se and are augmented by face immersion [29]. The constriction of intramuscular and dermal vessels results in an increased total peripheral resistance and thus in an increased blood pressure $[9,30]$. Due to peripheral vasoconstriction and reduced blood flow, the remaining circulating blood flow is redistributed to more hypoxia sensitive organs such as the brain $[19,25]$. In the present study, only minimal blood flow changes were seen in the descending aorta while blood flow in the ascending aorta and the carotid arteries massively increased, indicating that even the gastrointestinal tract is excluded from blood flow redistribution in the case of hypoxia. This perfusion preference of the cerebrum emphasises the efficiency of the body's compensatory mechanism to avoid hypoxic damage of the brain. Accordingly, cerebral MRI showed no case of acute ischemia-induced brain injury, indicating the effectiveness of the compensatory mechanisms, even in case of breathholds longer than 8 min (Table 1, subject 12).

Prolonged apnoea is not exclusively seen in breathhold divers, also patients with obstructive sleep apnoea (OSA) show compensatory mechanisms to avoid brain damage [31]. Patients with OSA show an increase in cerebral blood flow [32, 33], elevated sympathetic activity [34], elevated arterial blood pressure [35], and an increase in norepinephrine levels [31]. Interestingly, LV and right ventricular (RV) afterload are increased and cardiac arrhythmia is commonly seen [36]. OSA is independently associated with coronary artery disease, atherosclerosis, hypertension, stroke, endothelial function and myocardial infarction [37, 38]. A main problem in understanding the underlying pathophysiology stems from the lack of an adequate clinical model to simulate OSA [39]. So far, hypoxic gas mixtures have been used to mimic hypoxia in humans [40], but because of the resulting hyperventilation, these models are more representative for high altitude environments than for OSA. In addition, the transmissibility of animal models is also limited. Apnoea divers are mostly free of comorbidities, and our study shows that even a short episode of hypoxia affects the cardiovascular system. Therefore, voluntary extended breath-hold might be taken as a clinical relevant model to simulate short term changes due to hypoxia [41], although the exposure levels to hypoxemia differ significantly [41]. In this context it should be noted that this study was performed with trained athletes, and that a transfer of these findings to patients with cardiovascular diseases and obstructive sleep apnoea should be done with caution. 
Patent foramen ovale has been demonstrated to have a higher prevalence in patients with obstructive sleep aponoea compared to healthy controls, and is suspected to inrease nocturnal oxygen desaturation in these patients [42] and to enhance other pathologic conditions associated with OSA [43]. In both scuba and apnoea divers knowledge about the implications of a patent foramen ovale regarding incidence and severity of decompression sickness is scarce [44], especially because it is unkown if recurrent decompression sickness is a result of a patent foramen ovale, the inabiliy to adopt a more conservative diving style, or both [45]. In the present study, no relevant changes of $\mathrm{Qp} / \mathrm{Qs}$ (the stroke volume in the ascending aorta relative to the stroke volume in the pulmonary trunk) and thus no indication for a cardiac shunt, was found.

Cardiac dysrhythmia or irregular heartbeats (mainly premature ventricular excitations) were observed in 14 of 17 divers at the end of apnoea and during the early recovery phase (example shown in Additional file 1: Figure S1). It is tempting to speculate that the massive LV and RV dilatation triggers cardiac depolarization and repolarization. However, ECG quality was limited in this study and did not allow for a comprehensive analysis.

\section{Limitations}

Measurment accuracy (CMR and $\mathrm{SpO}_{2}$ ) might be limited at the end of apnoea due to e.g. motion artefacts (CMR), peripheral vasoconstriction $\left(\mathrm{SpO}_{2}\right)$, and other technical restrictions. Blood pressure data is not available as invasive blood pressure measurement was not performed due to ethical considerations and automatic non-invasive blood pressure measurement failed due to the high and dynamic changes in blood pressure during apnoea. Due to the chosen CMR imaging protocol with only limited coverage of the RV, neither volumetric nor functional RV data are available. Future studies should also focus on effects of hypxoxia on pulmonary vasoconstriction and their effects on the RV function.

\section{Conclusion}

Compensatory effects of prolonged apnoea, including a massive LV dilatation and an increase in norepinephrine levels, substantially burden the cardiovascular system. This hemodynamic cardiac stress results in increased hs-cT and NT-pro-BNP, and leads to a reduction of FS. CMR tissue characterisation did not reveal acute myocardial injury, indicating that the resulting cardiovascular stress does not exceed compensatory short-term physiological limits in healthy elite divers. However, these compensatory mechanisms could overly tax those limits in subjects with pre- existing cardiac disease. Also, repetitive apnoea over decades, rather than over years as observed in our study population, may reveal different findings and may have a different impact on the cardiovascular system. For divers interested in competitive apnoea diving, a comprehensive medical exam with a special focus on the cardiovascular system may be warranted.

\section{Additional file}

Additional file 1: Figure S1. Screenshots of monitored arrhythmia in different subjects (a-d) and in early recovery phase (e). (JPG $161 \mathrm{~kb}$ )

\begin{abstract}
Abbreviations
BMI : Body mass index; BNP: Brain natriuretic peptide; BSA: Body surface area; CCA: Common carotid arteries; CMR: Cardiovascular magnetic resonance; CO: Cardiac output; CT: Cardiac troponin; DWI: Diffusion weighted imaging; EDD: End-diastolic dimension; EDV: End-diastolic volume; EF: Ejection fraction; ESD: End-systolic dimension; ESV: End-systolic volume; FLAIR: Fluid attenuated inversion recovery; FS : Fractional shortening; HR: Heart rate; hs-cT: High sensitive troponin; LV: Left ventricle/left ventricular; MRI : Magnetic resonance imaging; NT-pro-BNP : N-terminal pro-hormone of brain natriuretic peptide; OSA: Obstructive sleep apnoea; $\mathrm{pO}_{2}$ : Partial pressure of $\mathrm{O}_{2}$; PWI: Pressure work index; Qmean: Mean flow; ROI: Region of interest; RV: Right ventricle/ right ventricular; SD: Standard deviation; $\mathrm{SpO}_{2}$ : Peripheral oxygen saturation; SV: Stroke volume; TSE: Turbo spin echo; $V_{\text {max }}$ : Maximum velocity; $V_{\text {mean }}$ : Mean velocity
\end{abstract}

\section{Acknowledgements}

The authors thank all of the volunteers who participated in the study. We furthermore thank A. Carstensen and M. Schmidt for their technical support.

\section{Availability of data and materials}

The datasets used and/or analysed during the current study are available from the corresponding author on reasonable request. Personal data or any data, which allow conclusions on clearly identified or identifiable individuals, are not available.

\section{Authors' contributions}

$L E$, JD, CPN and BZ designed and planned the study and drafted the manuscript. JAL, JML, RCDP analysed datasets and gave technical support. JAL and RCDP drafted paragraphs of the manuscript. FE, RF, JN performed statistical analysis. BSW, HHS, AH helped to design the study and revised the manuscript. All authors read and approved the final manuscript.

\section{Ethics approval and consent to participate}

This prospective single-centre study was registered under ClinicalTrials.gov (identifier: NCT02280226) and additionally approved by the institutional ethics committee review board of Bonn; Germany (373/13). Participants received an information sheet 14 days prior to the study. Informed consent was individually obtained from all participants included in the study. This study was not funded and all contributors participated on a voluntary basis.

\section{Competing interests}

The authors declare that they have no competing interests.

\section{Publisher's Note}

Springer Nature remains neutral with regard to jurisdictional claims in published maps and institutional affiliations.

\section{Author details}

${ }^{1}$ Department of Anaesthesiology and Intensive Care Medicine, University Hospital of Bonn, Bonn, Germany. ${ }^{2}$ Department of Radiology, University Hospital of Bonn, Bonn, Germany. ${ }^{3}$ Department of Radiology, University Hospital of Cologne, Cologne, Germany. ${ }^{4}$ Institute for Medical Biometry, Informatics and Epidemiology (IMBIE), Bonn, Germany. ${ }^{5}$ Medical Biometry, Information Technology and Epidemiology, University of Bonn, Bonn, Germany. 


\section{Received: 16 October 2017 Accepted: 8 May 2018} Published online: 18 June 2018

\section{References}

1. Chen L, Sica AL, Greenberg H, Scharf SM. Role of hypoxemia and hypercapnia in acute cardiovascular response to periodic apneas in sedated pigs. Respir Physiol. 1998;111:257-69.

2. O'Donnell CP, King ED, Schwartz AR, Robotham JL, Smith PL. Relationship between blood pressure and airway obstruction during sleep in the dog. $J$ Appl Physiol. 1994;77:1819-28.

3. Eichhorn L, Erdfelder F, Kessler F, Doerner J, Thudium MO, Meyer R, et al. Evaluation of near-infrared spectroscopy under apnea-dependent hypoxia in humans. J Clin Monit Comput. 2015:29:749-57.

4. Eichhorn L, Kessler F, Böhnert V, Erdfelder F, Reckendorf A, Meyer R, et al. A model to simulate clinically relevant hypoxia in humans. J Vis Exp JoVE. 2016:e54933.

5. Heusser K, Dzamonja G, Tank J, Palada I, Valic Z, Bakovic D, et al. Cardiovascular regulation during apnea in elite divers. Hypertension. 2009;53:719-24.

6. Overgaard K, Friis S, Pedersen RB, Lykkeboe G. Influence of lung volume, glossopharyngeal inhalation and $\mathrm{P}(\mathrm{ET}) \mathrm{O} 2$ and $\mathrm{P}(\mathrm{ET}) \mathrm{CO} 2$ on apnea performance in trained breath-hold divers. Eur J Appl Physiol. 2006;97:158-64.

7. Willie CK, Ainslie PN, Drvis I, MacLeod DB, Bain AR, Madden D, et al. Regulation of brain blood flow and oxygen delivery in elite breath-hold divers. J Cereb Blood Flow Metab Off J Int Soc Cereb Blood Flow Metab. 2015;35:66-73

8. Lindholm P, Lundgren CE. The physiology and pathophysiology of human breath-hold diving. J Appl Physiol. 2009;106:284-92.

9. Perini R, Tironi A, Gheza A, Butti F. Moia C, Ferretti G. Heart rate and blood pressure time courses during prolonged dry apnoea in breath-hold divers. Eur J Appl Physiol. 2008;104:1-7.

10. Marabotti C, Piaggi P, Menicucci D, Passera M, Benassi A, Bedini R, et al. Cardiac function and oxygen saturation during maximal breath-holding in air and during whole-body surface immersion. Diving Hyperb Med. 2013:43:131-7.

11. Gopal AS, King DL, King DL, Keller AM, Rigling R. Left ventricular volume and endocardial surface area by three-dimensional echocardiography: comparison with two-dimensional echocardiography and nuclear magnetic resonance imaging in normal subjects. J Am Coll Cardiol. 1993;22:258-70.

12. Sprinkart AM, Luetkens JA, Träber F, Doerner J, Gieseke J, Schnackenburg B, et al. Gradient spin Echo (GraSE) imaging for fast myocardial T2 mapping. J Cardiovasc Magn Reson. 2015;17:12

13. Mosteller RD. Simplified calculation of body-surface area. N Engl J Med. 1987;317:1098

14. Lewis RP, Sandler H. Relationship between changes in left ventricular dimensions and the ejection fraction in man. Circulation. 1971:44:548-57.

15. Hoeft A, Sonntag H, Stephan H, Kettler D. The influence of anesthesia on myocardial oxygen utilization efficiency in patients undergoing coronary bypass surgery. Anesth Analg. 1994;78:857-66.

16. Eichhorn L, Erdfelder F, Kessler F, Dolscheid-Pommerich RC, Zur B, Hoffmann $\mathrm{U}$, et al. Influence of apnea-induced hypoxia on catecholamine release and cardiovascular dynamics. Int J Sports Med. 2017:38:85-91.

17. Pingitore A, Gemignani A, Menicucci D, Di Bella G, De Marchi D, Passera M, et al. Cardiovascular response to acute hypoxemia induced by prolonged breath holding in air. Am J Physiol Heart Circ Physiol. 2008;294:H449-55.

18. Batinic T, Utz W, Breskovic T, Jordan J, Schulz-Menger J, Jankovic S, et al. Cardiac magnetic resonance imaging during pulmonary hyperinflation in apnea divers. Med Sci Sports Exerc. 2011;43:2095-101.

19. Cross TJ, Kavanagh JJ, Breskovic T, Johnson BD, Dujic Z. Dynamic cerebral autoregulation is acutely impaired during maximal apnoea in trained divers. PLoS One. 2014:9:e87598.

20. Laurino M, Menicucci D, Mastorci F, Allegrini P, Piarulli A, Scilingo EP, et al. Mind-body relationships in elite apnea divers during breath holding: a study of autonomic responses to acute hypoxemia. Front Neuroengineering. 2012;5:4.

21. Costalat G, Pichon A, Joulia F, Lemaitre F. Modeling the diving bradycardia: toward an "oxygen-conserving breaking point"? Eur J Appl Physiol. 2015; 115:1475-84.

22. Hoeft A, Korb H, Hellige G, Sonntag H, Kettler D. The energetics and economics of the cardiac pump function. Anaesthesist. 1991;40:465-78.

23. Schipke JD. Cardiac efficiency. Basic Res Cardiol. 1994;89:207-40.

24. Palada I, Obad A, Bakovic D, Valic Z, Ivancev V, Dujic Z. Cerebral and peripheral hemodynamics and oxygenation during maximal dry breathholds. Respir Physiol Neurobiol. 2007;157:374-81.
25. Eichhorn L, Erdfelder F, Kessler F, Dolscheid-Pommerich RC, Zur B, Hoffmann $\mathrm{U}$, et al. Influence of apnea-induced hypoxia on catecholamine release and cardiovascular dynamics. Int J Sports Med. 2016;

26. Nakagawa O, Ogawa Y, Itoh H, Suga S, Komatsu Y, Kishimoto I, et al. Rapid transcriptional activation and early mRNA turnover of brain natriuretic peptide in cardiocyte hypertrophy. Evidence for brain natriuretic peptide as an "emergency" cardiac hormone against ventricular overload. J Clin Invest. 1995;96:1280-7.

27. Sato Y, Yamada T, Taniguchi R, Nagai K, Makiyama T, Okada H, et al. Persistently increased serum concentrations of cardiac troponin $\mathrm{T}$ in patients with idiopathic dilated cardiomyopathy are predictive of adverse outcomes. Circulation. 2001;103:369-74.

28. Andersson JPA, Linér MH, Rünow E, Schagatay EKA. Diving response and arterial oxygen saturation during apnea and exercise in breath-hold divers. J Appl Physiol. 2002;93:882-6.

29. Andersson JPA, Evaggelidis L. Arterial oxygen saturation and diving response during dynamic apneas in breath-hold divers. Scand J Med Sci Sports. 2009;19:87-91.

30. Foster GE, Sheel AW. The human diving response, its function, and its control. Scand J Med Sci Sports. 2005;15:3-12.

31. Bisogni V, Pengo MF, Maiolino G, Rossi GP. The sympathetic nervous system and catecholamines metabolism in obstructive sleep apnoea. J Thorac Dis. 2016:8:243-54

32. Busch DR, Lynch JM, Winters ME, McCarthy AL, Newland JJ, Ko T, et al. Cerebral blood flow response to hypercapnia in children with obstructive sleep apnea syndrome. Sleep. 2016;39:209-16.

33. Alex R, Bhave G, Al-Abed MA, Bashaboyina A, lyer S, Watenpaugh DE, et al. An investigation of simultaneous variations in cerebral blood flow velocity and arterial blood pressure during sleep apnea. Conf Proc Annu Int Conf IEEE Eng Med Biol Soc IEEE Eng Med Biol Soc Annu Conf. 2012;2012:5634-7.

34. Gilmartin GS, Tamisier R, Curley M, Weiss JW. Ventilatory, hemodynamic, sympathetic nervous system, and vascular reactivity changes after recurrent nocturnal sustained hypoxia in humans. Am J Physiol Heart Circ Physiol. 2008;295:H778-85

35. Mohsenin V. Obstructive sleep apnea and hypertension: a critical review. Curr Hypertens Rep. 2014;16:482.

36. Kasai T, Bradley TD. Obstructive sleep apnea and heart failure: pathophysiologic and therapeutic implications. J Am Coll Cardiol. 2011;57:119-27.

37. Geovanini GR, Gowdak LHW, Pereira AC, Danzi-Soares NJ, LOC D, Poppi NT, et al. OSA and depression are common and independently associated with refractory angina in patients with coronary artery disease. Chest. 2014;146:73-80.

38. Nieto FJ, Young TB, Lind BK, Shahar E, Samet JM, Redline S, et al. Association of sleep-disordered breathing, sleep apnea, and hypertension in a large community-based study. Sleep heart health study. JAMA. 2000;283:1829-36.

39. Drager LF, Polotsky VY, O'Donnell CP, Cravo SL, Lorenzi-Filho G, Machado BH. Translational approaches to understanding metabolic dysfunction and cardiovascular consequences of obstructive sleep apnea. Am J Physiol Heart Circ Physiol. 2015;309:H1101-11.

40. Kolb JC, Ainslie PN, Ide K, Poulin MJ. Protocol to measure acute cerebrovascular and ventilatory responses to isocapnic hypoxia in humans. Respir Physiol Neurobiol. 2004;141:191-9.

41. Ivancev V, Bakovic D, Obad A, Breskovic T, Palada I, Joyner MJ, et al. Effects of indomethacin on cerebrovascular response to hypercapnea and hypocapnea in breath-hold diving and obstructive sleep apnea. Respir Physiol Neurobiol. 2009;166:152-8.

42. Shaikh ZF, Jaye J, Ward N, Malhotra A, de Villa M, Polkey MI, et al. Patent foramen ovale in severe obstructive sleep apnea: clinical features and effects of closure. Chest. 2013:143:56-63.

43. Rimoldi SF, Ott S, Rexhaj E, de Marchi SF, Allemann Y, Gugger M, et al. Patent foramen Ovale closure in obstructive sleep apnea improves blood pressure and cardiovascular FunctionNovelty and significance. Hypertension. 2015;66:1050-7

44. Smart D, Mitchell S, Wilmshurst $P$, Turner M, Banham N. Joint position statement on persistent foramen ovale (PFO) and diving. South Pacific underwater medicine society (SPUMS) and the United Kingdom sports diving medical committee (UKSDMC). Diving Hyperb Med. 2015;45: 129-31.

45. Lafère P, Balestra C, Caers D, Germonpré P. Patent Foramen Ovale (PFO), personality traits, and iterative decompression sickness. Retrospective analysis of 209 cases. Front Psychol. 2017:8:1328. 